\title{
The demographic profile and the management of infantile inguinal hernia: a 3-year's review
}

\author{
Jayalaxmi Shripati Aihole*
}

\begin{abstract}
Background: Inguinal hernia in neonates and infants including children is as a result of failure of processes vaginalis to close. Once diagnosed, it should be promptly repaired on elective basis to prevent possible risk of bowel incarceration. The purpose of this study was to evaluate the clinical profile, management, and outcome of infantile inguinal hernia.

Methods: Aim of this prospective clinical study was to clinically evaluate the infants with clinical diagnosis of inguinal hernia admitted in our tertiary child care institute from January 2014 to December 2017 over a period of three years. The design of this study was to assess the clinical profile, management and outcome of infantile inguinal hernia. Study was conducted in a tertiary care neonatal and paediatric referral centre in southern India. Infants less than 1 year including neonates were selected for this study on the basis of inclusion and exclusion criteria. The maximum follow-up period was 5 years.
\end{abstract}

Results: A total of 118 infants admitted with clinical diagnosis of inguinal hernia were included in the present study. They were grouped as per their clinical diagnosis and age on admission into two groups; 0 to 6 months as group I and more than 6 months to 12 months as group II. All of them underwent surgical repair as soon as diagnosed. Overall survival rate was $100 \%$. There was no operative mortality 0/118 (0\%). Rate of recurrence was $0.034 \%$ without any surgical site infections.

Conclusion: Early surgical intervention in the form of inguinal herniotomy is the most appropriate management of inguinal hernia in infants including the neonates as soon as diagnosed on elective basis.

Keywords: Inguinal hernia, Neonates, Processus vaginalis, Herniotomy

\section{Background}

Inguinal hernias in infants and young children are the result of persistent patent processus vaginalis. Once diagnosed, an inguinal hernia should be promptly repaired on an elective basis to prevent the risk of incarceration. Aim of the present study was to describe the clinical profile, management and its anaesthetic and surgical challenges in infantile inguinal hernia including neonates.

\footnotetext{
*Correspondence: jayalaxmisaihole@yahoo.com; jaihole4@gmail.com
} Department of Paediatric Surgery, IGICH Bangalore, Karnataka, India

\section{Methods}

This was a prospective clinical observational study conducted in a tertiary care centre in Bengaluru, southern India, in neonates and infants less than a year over a period of three years, with the clinical diagnosis of inguinal hernia, International Classification of Diseases [ICD] 2018, K40.0, K40.2, K40.3, and K40.9 included; between 1st January 2014, and 31st December 2017.

Predesigned proforma was followed to collect data from medical records section, parents including caretakers. Data were collected on structured proforma using Microsoft (MS) Excel Version 2010. All the statistical analysis was performed using SPSS software version 18.0. 
(IBM, New York: Routledge). Neonates from day 0 to day 30 including infants less than a year of age referred with clinical diagnosis of inguinal hernia were included in the study. Diagnosis of inguinal hernia was made in the majority by clinical examination alone. Imaging studies like ultrasonography was infrequently used to look for the contents except in female infants. 2D echocardiography was used whenever there was clinically significant murmur or in syndrome/dysmorphic babies. Babies with congenital hydrocele were excluded from this study. We did not encounter any baby with femoral hernia during this present study.

\section{Statistical analysis}

Factors statistically analysed were, age in months, birth weight in $\mathrm{kgs}$, weight at the time of surgery, age on admission, gender, laterality, synchronicity, duration of symptoms, reducibility, and haemoglobin level at the time of surgery, length of hospital stay, infection, recurrence, morbidity and mortality (Table 1 ). Categorical variables were reported using frequencies and percentiles. Student's $t$ test and Chi-square test were used to find association between variables. A $P$ value of $<0.05$ was considered statistically significant.

Table 1 Clinical profile of infantile inguinal hernia

\begin{tabular}{|c|c|c|c|c|}
\hline Parameters & $\begin{array}{l}\text { Gl } \\
0-6 \text { months }\end{array}$ & $\begin{array}{l}\text { GII } \\
\text { 6-12 months }\end{array}$ & $P$ value & Significance \\
\hline No of study subjects-118 & $N=89(75.4 \%)$ & $N=29(24.6 \%)$ & - & - \\
\hline Age (days) & $79 \pm 36$ & $312 \pm 52.8$ & $<0.001$ & $\mathrm{HS}$ \\
\hline \multicolumn{5}{|l|}{ Gender } \\
\hline \multicolumn{5}{|l|}{ Male } \\
\hline Female & $70(78.65 \%)$ & $24(82.75 \%)$ & - & - \\
\hline Ratio & $19(21.3 \%)$ & $5(17.24 \%)$ & & \\
\hline $\begin{array}{l}\text { Duration of symptoms (days) } \\
\text { (Mean } \pm \text { SD) }\end{array}$ & $3.6: 1$ & $4.8: 1$ & & \\
\hline $\begin{array}{l}\text { Birth wt (Kgs) } \\
\text { (Mean } \pm \text { SD) }\end{array}$ & $3 \pm 3$ & $2.63 \pm 0.4$ & $>0.05$ & NS \\
\hline $\begin{array}{l}\text { Wt at time of surgery (Kgs) } \\
\text { (Mean } \pm \text { SD) }\end{array}$ & $3.82 \pm 1.12$ & $8 \pm 1.0$ & $<0.0001$ & HS \\
\hline Preterm babies (28-37 weeks) & $22(24.71 \%)$ & $0(0 \%)$ & - & - \\
\hline $\begin{array}{l}\mathrm{LIH}- \\
\mathrm{RIH}- \\
\mathrm{B} / \mathrm{L}-\mathrm{IH} \\
\text { Metachronous } \mathrm{IH}-\end{array}$ & $\begin{array}{l}38(42.66 \%) \\
31(34.83 \%) \\
18(20.2 \%) \\
2(2.24 \%)\end{array}$ & $\begin{array}{l}14(48.27 \%) \\
10(34.48 \%) \\
5(17.24 \%) \\
0\end{array}$ & - & - \\
\hline HB (gms) (Mean \pm SD) & $11 \pm 1.57$ & $11 \pm 1.0$ & $>0.05$ & NS \\
\hline $\begin{array}{l}\text { Reducible hernia- } \\
\text { Special contents- } \\
\text { Irreducible hernia- } \\
\text { Contents-ovary }\end{array}$ & $\begin{array}{l}81(91 \%) \\
{ }^{*} \mathrm{Ovary}-3(3.7 \%) \\
{ }^{*} \mathrm{AH}-2(2.46 \%) \\
{ }^{*} 8(8.9 \%) \\
\mathrm{R}-3(37.5 \%) \\
\mathrm{L}-5(62.5 \%) \\
2(25 \%)\end{array}$ & $\begin{array}{l}26(89.65 \%) \\
{ }^{*} \text { Ovary- } 1(3.8 \%) \\
{ }^{*} \text { Chylous ascites-1 (3.8\%) } \\
{ }^{*} \text { Enterocele-1 (3.8\%) } \\
{ }^{*} 3(10.34 \%) \\
\text { R-1 }(33.3 \%) \\
\text { L-2 }(66 \%) \\
1(33.3 \%)\end{array}$ & - & - \\
\hline Lohs (days) (Mean \pm SD) & $5 \pm 5$ & $3.55 \pm 2.10$ & 0.149 & NS \\
\hline Syndromic babies & $4(4.49 \%)$ & $1(0.0345 \%)$ & - & - \\
\hline Other procedures & Mitchell banks'-3 (3.3\%) & Mesh repair-1 (2.9\%) & - & - \\
\hline Recurrence & $1(1.12 \%)$ & $0(0.0345 \%)$ & - & - \\
\hline Infection & 0 & 0 & - & - \\
\hline Surgical morbidity & $1(0.85 \%)$ & 0 & - & - \\
\hline General morbidity & 1 & 1 & & \\
\hline General mortality & 0 & $1(0.847 \%)$ & & \\
\hline
\end{tabular}

$L I H$ left inguinal hernia, $R I H$ right inguinal hernia, $B L I H$ bilateral inguinal hernia, $H B$ hemoglobin, $A H$ Amyand's hernia, $L O H$ lenght of hospital stay 


\section{Results}

A total of 118 infants with inguinal hernia were enrolled in the present study. The congenital inguinal hernias were diagnosed by taking a detailed history from the parents as well as caretakers in pre designed proformas, followed by clinical examinations, investigations if required.

The hernial site, size, variability, reducibility, cry impulse or any underlying straining for micturition and the presence or absence of the testis in the scrotal sac were also noted (Fig. 1). The respiratory system, the cardiovascular system and the abdomen were also examined for any associated congenital/acquired conditions. All the babies were subjected to routine complete hemogram. Abdominal ultrasound was done in clinically doubtful cases, including in female babies to look for content of the sac and in irreducible inguinal hernias. 2D echocardiography was advised in dysmorphic, syndromic babies as well as for those with clinically significant murmur.

All of them underwent surgical repair as soon as diagnosed. There were 89/118 (75.4\%) infants in group I and $29 / 118$ (24.6\%) in group II. Mean age of infants at admission in group I was $79 \pm 36$ (days) and in group II was $312 \pm 52.8$ with a $P$ value of $<0.001$ which was highly significant (Table 1). Left-sided hernia predominated in GI 38 (42.66\%), with right side 31 (34.83\%) with 18 (20.2\%) were bilateral (synchronous) and $2(2.24 \%)$ were metachronus hernias. In GII left were 14 (48.27\%), right were $10(34.48 \%)$, and $5(17.24 \%)$ were bilateral without any case of metachronous hernia. Reducible hernia in GI were 81 (91\%) and irreducible were $8(8.9 \%)$ with left $5(62.5 \%)$, right $3(37.5 \%)$, whereas in GII reducible ones were $26(89.65 \%)$ and irreducible ones were 3 (10.34\%), with left 2 (66\%) and right 1 (33.3\%) (Table 1). All of them underwent standard Ferguson's hernia repair under general anaesthesia except 3 (3.3\%) neonates in GI underwent Mitchells Banks' repair and one (2.9\%) polypropylene mesh repair in GII.

Syndromic babies in GI were 4 (4.49\%) which included Down's syndrome, Cutis laxa and Edward's syndromes; 1 case of Cutis laxa syndrome (3.44\%) in GII. The isolated syndromic babies were 2 (Down's and Cutis laxa) in GI and nil in GII. Two babies (2.24\%) with Edwards's syndrome had associated other anomalies in GI and 1 baby with Cutis laxa syndrome had other anomalies (3.44\%) in GII (Table 2). 19 babies (21.34\%) had non-syndromic conditions in GI and 9 (31\%) in GII.

No emergency surgical intervention was required in incarcerated cases, all of which were operated on

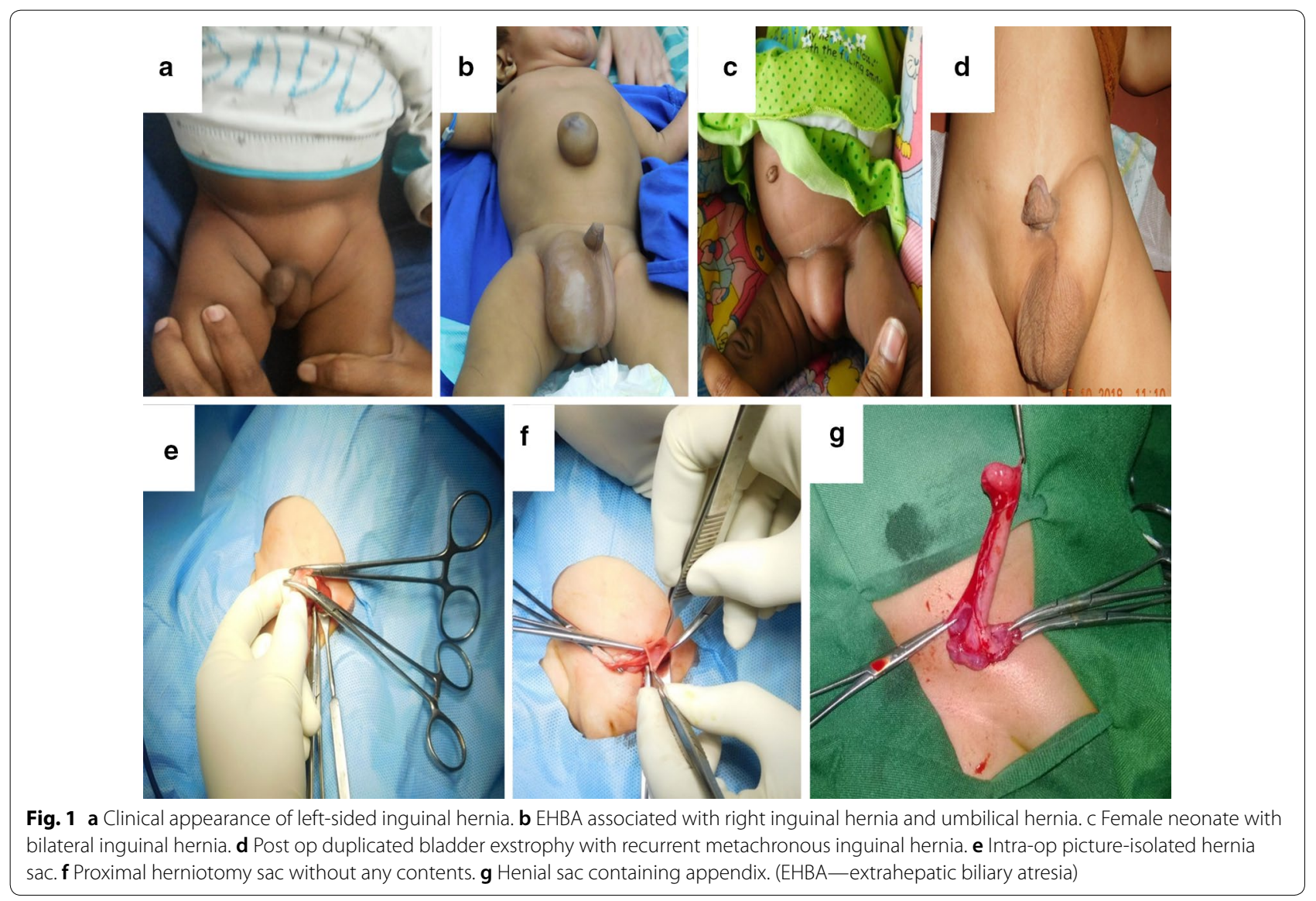


Table 2 Syndrome/conditions associated with infantile inguinal hernia

\begin{tabular}{|c|c|c|}
\hline No of study subjects-118 & $\begin{array}{l}\text { Gl-(0-6 months) } \\
\text { N-89 }\end{array}$ & $\begin{array}{l}\text { GII (6-12 months) } \\
\text { N-29 }\end{array}$ \\
\hline Isolated syndromic & $\begin{array}{l}2(2.24 \%) \\
\text { DS-1 }(1.12 \%) \\
\text { CL-1 }(1.12 \%)\end{array}$ & 0 \\
\hline Syndromic asso with other cong anomalies & $\begin{array}{l}2(2.24 \%) \\
{ }^{*} \text { Edward syndrome + CTEV + webbed neck -1 (1.12\%) } \\
{ }^{*} \text { Edwards syndrome + RDS-1 }(1.12 \%)\end{array}$ & $\begin{array}{l}1(3.44 \%) \\
{ }^{*} \mathrm{CL}+\mathrm{HUN}+\text { Pectus excavatum }\end{array}$ \\
\hline Non syndromic Conditions & 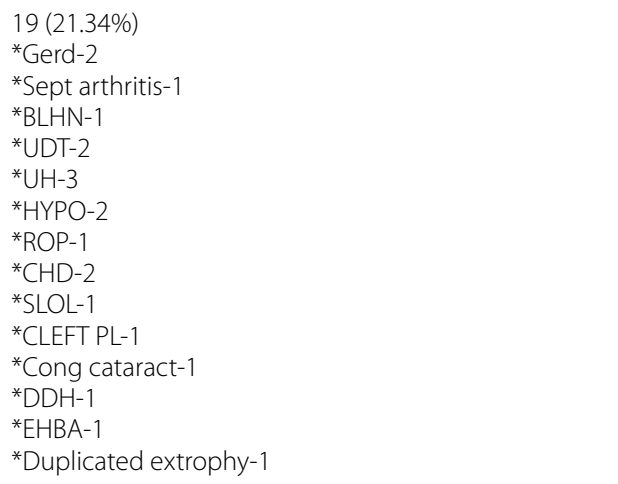 & $\begin{array}{l}9(31 \%) \\
{ }^{*} \text { EEC + Cervical MMC + Spina } \\
\text { bifida + Small Phallus } \\
{ }^{*} \text { Chylous Ascites-1 } \\
{ }^{*} \text { CHD-3 } \\
{ }^{*} \text { GDD + Spastic Diplegia-1 } \\
\text { *LIMB anomalies-1 } \\
\text { *UDT-2 }\end{array}$ \\
\hline Other surgeries & $\begin{array}{l}7(7.8 \%) \\
{ }^{*} \text { Orchidopexy-2 (2.24\%) } \\
{ }^{*} \text { Circumcision-1 } \\
{ }^{*} \text { Arthrotomy-1 } \\
{ }^{*} \text { Cataract surgery }(\mathrm{IOL})-1 \\
{ }^{*} \text { Kasai's procedure-1 } \\
\text { *Excision of duplicated Extrophy-1 }\end{array}$ & $\begin{array}{l}5(17.24 \%) \\
{ }^{*} \text { Orchidopexy-2 (6.8\%) } \\
{ }^{*} \text { Circumcision-1 } \\
{ }^{*} \text { EEC + MMC repair-1 }\end{array}$ \\
\hline
\end{tabular}

DS down's syndrome, CL cutis laxa, CTEV congenital talipus equino varus, RDS respiratory distress syndrome, HUN hydroureteronephrosis, GERD gastroesophageal reflux syndrome, $B L H N$ bilateral hydronephrosis, UDT undescended testis, UH umbilical hernia, $H Y P O$ hypospadias, $R O P$ retinopathy of prematurity, $C H D$ congenital heart disease, $S L O L$ subluxation of lens, $D D H$ developmental dysplasia of hip, EHBA extrahepatic biliary atresia, $E E C$ extrophy epispadais complex, $M M C$ myelomengocele, GDD global developmental delay, CLEFT PL Cleft Palte

electively after 3 to 5 days following manual reduction. None of our babies underwent umbilical hernia repair at the time of herniotomy (Fig. 2).

In our study we found, age on admission, weight at the time of surgery and duration of symptoms highly significant statistically (Table 1).

\section{Discussion}

Present study was a prospective observational cohort study conducted on infants including neonates diagnosed and admitted with inguinal hernia. Inguinal and scrotal swellings are the common swellings encountered in infants and children. Most common is hernial swelling which is due to persistence of processus vaginalis which is present during intrauterine gestation for ease of descent of testis. The incidence of inguinal hernia (IH) in full term infants is 3.5 to $5.0 \%$, whereas in premature and low birth weight (LBW) babies is 44 to $55 \%$ [1-3]. In our study, we found $22(24.71 \%)$ of premature babies in GI and none in GII which were managed successfully.

Bronsther et al. have reported that, one-third of the patients in their series were of less than 6 months of age
[4]. However, in our series, babies less than 6 months (GI) constituted around three times the infants in GII. Since ours is the only neonatal and paediatric referral centre in southern India; babies are referred to us quiet early.

Among GI, we had 70 (78.65\%) males, 19 (21.3\%) females with a ratio of 3.6:1, whereas in GII we had 24 $(82.75 \%)$ males, 5 (17.24\%) females, with a ratio of 4.8:1. Hence, the male predominance was seen in both the groups. Literature review reveals the ratio as, $6: 1$ by Poenarau et al., 7:1 by Grossfeld et al., 9:1 by Ravikumar et al. and $11.5: 1$ by Jadhav et al. [5-7]. Ours is the only series, which showed lower sex ratio despite lower socioeconomic status and the general public awareness.

Left-sided hernia predominated in GI 38 (42.66\%), right side 31 (34.83\%) with 18 (20.2\%) were bilateral (synchronous) and $2(2.24 \%)$ were metachronus hernias (Fig. 1a, b). In GII left were 14 (48.27\%), right of 10 (34.48\%) and 5 $(17.24 \%)$ were bilateral without any case of metachronous hernia. Literature confirms the predominance of rightsided inguinal hernias, but our study revealed the just the opposite. The studies of Rowe et al., and Grosfeld et al., reported an incidence of $55-60 \%$ of the inguinal hernias 


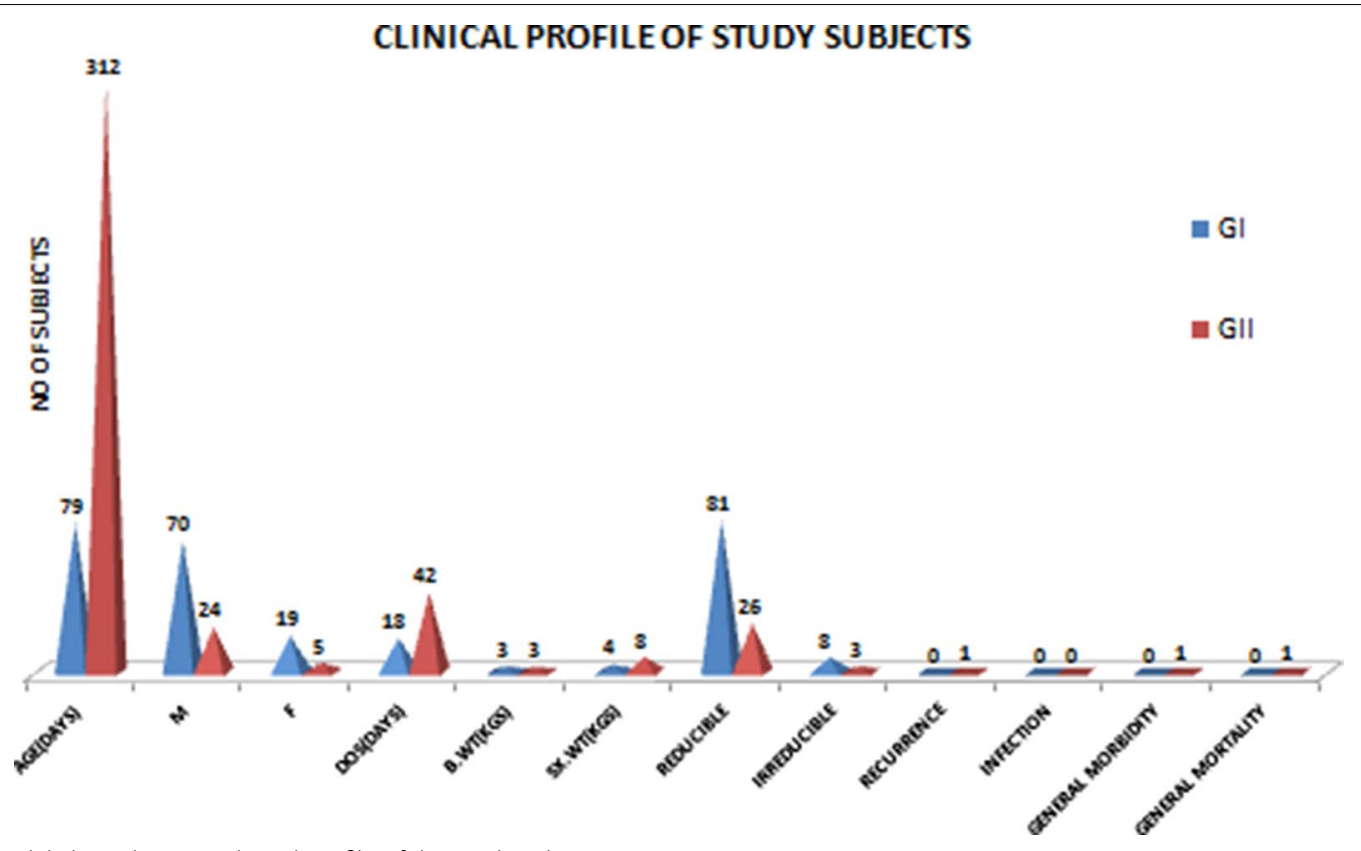

Fig. 2 Pyramidal chart showing clinical profile of the study subjects

on the right side, that of $25 \%$ on the left side and that of $15 \%$ bilaterally [2, 3, 8, 9] (Fig. 3).

Hoshino et al. [10] study confirms that babies operated for left-sided inguinal hernia repair had a 5.5-fold incidence of metachrnous hernia but surprisingly in our study we did not find its correlation [10]. We encountered only $2(2.24 \%)$ cases of metachronous hernias in GI, and none in GII. Crankson et al. and Ballantyne et al. states

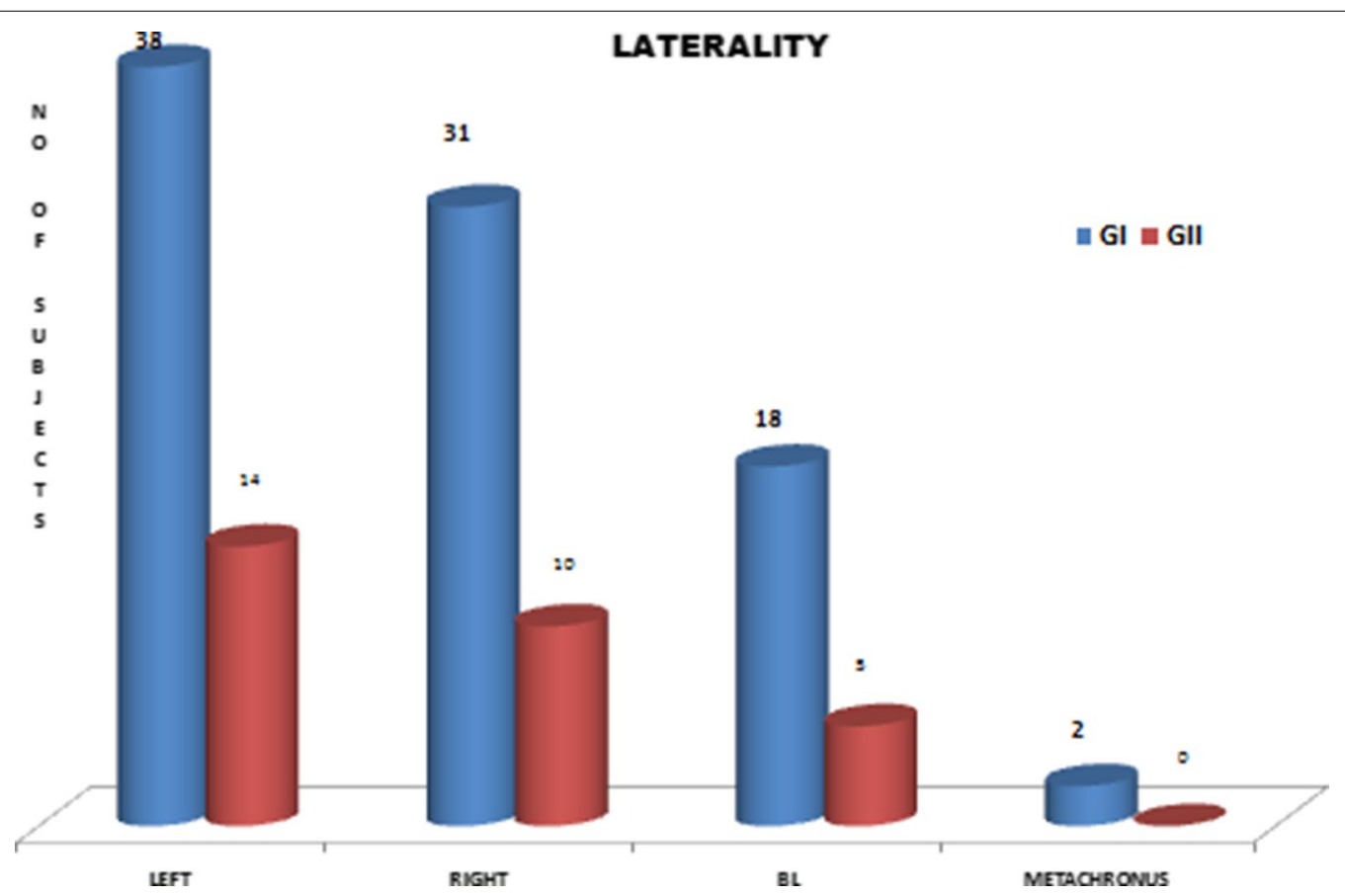

Fig. 3 Bar chart showing laterality of inguinal hernia in study subjects (bl-bilateral) 
that, because of low occurrence of metachronous hernia, contra lateral inguinal exploration is not justified $[11,12]$. In our institute also, we generally do not follow the policy of the contra lateral groin exploration routinely.

Duration of symptoms in days in the both groups was found to be $18 \pm 15$ and $42.97 \pm 56.28$ in days, respectively, with a $P$ value of $<0.0001$, which was highly significant statistically. We found only one article where duration of symptoms correlated with our study by Kumar et al. $[13,14]$.

We had only three babies less than a month whose birth weight was above $2 \mathrm{~kg}$, who were operated for hernia, and hence, they were monitored in neonatal intensive care unit (NICU) for a day or two post operatively and discharged uneventfully immediately after that. Very low birth weight premature infants with severe co morbidities are more likely to develop postoperative respiratory and cardiac events; hence a close observation in the NICU is advised for these babies.

22 (24.71\%) babies were premature (28-33 weeks) in GI and none in GII, presenting during early gestation which were managed successfully.

Birth weight (kgs) in both the groups were $3 \pm 3$ and $2.63 \pm 0.4$, respectively, with a $P$ value of $>0.05$ which was not significant statistically. Crankson et al. and Kreiger et al. preferred to do hernitomy in premature babies just before their discharge from nicu, same protocol was applied in our babies [11, 13]. De Goede and Vaos et al. stated that lower weight at the time of surgery was not a contradiction of surgery $[15,16]$.

Weight at the time of surgery in both groups was $3.82 \pm 1.12$ and $8 \pm 1.0$, respectively, with a $P$ value of $<0.0001$ which was highly significant statistically which was correlated well with $\mathrm{Yu}$-Li Lin et al. study [17]; in which they stated that no operation was postponed due to younger age or lower body weight, the same protocol was applied in our institute. Our babies had average of haemoglobin (HB) of 11 in both groups. Those who had $\mathrm{HB}$ of less than 10 were given haematinics and kept under close observation till surgery.

Two neonates in GI required blood transfusion due to exaggerated physiological anaemia to stabilise them for anaesthesia as well as for surgical challenge. In a study by Ozdemir et al., their babes had HB of 9 [18].

In GI, 81 (91\%) had reducible inguinal hernia, 8 $(8.9 \%)$ were irreducible, whereas in GII, 26 (89.65\%) were reducible and $3(10.34 \%)$ had irreducible inguinal hernia. All irreducible or incarcerated inguinal hernias at presentation were reduced by manual reduction of taxis manoeuvre by attending paediatric surgeon including the trainees at outpatient department as well as in the emergency room. Following reduction, they were planned for elective hernia repair once the baby is stabilised, during the same admission within 72 to $96 \mathrm{~h}$. Zamakhshary et al. reported that risk of incarceration is highest in less than 2-year-old children and within a wait period of 14 days [19]. Palmer et al. and Smith et al. reported majority of the incarcerated hernias $(83.3 \%)$ can be reduced by non operative manual reduction of taxis $[20,21]$. None of our babies underwent emergency herniotomy and none of our babies had ischaemic/gangrenous intestinal segments during the procedure. None of our babies underwent laparoscopic hernia repair.

Rowe et al. reports incarceration more on right-sided inguinal hernias (17\%) compared to left $(7 \%)$ in their series; whereas, our result shows just the opposite; having left-sided hernia presenting with irreducibility 5 (62.5\%) in GI and 2 (66\%) in GII. Rowe et al., recommends elective surgery after a reduction, since it has a lower rate of complications as compared to an emergency surgery $(1.7 \%$ vs. $22.1 \%)$ [6, 8, 9, 22]. In our institute also, we operate these babies as soon as diagnosed during the same admission electively.

Amongst the reducible hernias, we had 2 (2.46\%) neonates with Amyand's hernia containing normal appendix on right side type 1 as per Losonoff and Bassons classifications one in male and another one in a female neonate without any history suggestive of appendicitis, detected during the procedure; hence appendix was preserved. As per literature Amyand's hernia usually presents acutely with scrotal or tender swelling in the groin region; but finding normal appendix without any symptoms is rare [22, 23]; same was witnessed in our case (Figs. 1g, 2).

We had $3(3.7 \%)$ cases of hernial sac containing ovary amongst which, one had torted ovary; which could be detorsed and preserved in GI and one normal ovary (3.8\%) in GII. Laing et al. stated that $15-20 \%$ of inguinal hernias in females do contain ovary and fallopian tubes [24]. Osifo et al. reported in their study that, out of 176 hernias, $145(82.4 \%)$ were found to contain ovary and fallopian tube, which is a very high percentage in comparison with that obtained in the present study which showed only case $3.8 \%$ of inguinal hernias containing normal ovary [25].

We had 2 (2.24\%) isolated syndromic cases, one was downs and another of cutis laxa syndrome in G1; none in GII. Two cases (2.24\%) of syndromic (Edward's) associated with other anomalies in GI and one case (3.44\%) of cutis laxa in GII (Table 2). 19 (21.34\%) non syndromic babies having other conditions in GI and 9 (31\%) in GII (Table 2) (Figs. 1c, 2).

Rescoria et al. stated that direct inguinal hernias are rare constitute $0.5 \%$ of all groin hernias [26]. We had only one case of direct inguinal hernia in GII with cutis laxa in which mesh repair was done primarily [27-29]. 
The Mitchell Bank's operation was performed in three neonates by single consultant, where herniotomy was done without opening the external oblique aponeurosis. However, all other babies underwent standard Ferguson's repair by all the consultants including the trainees in paediatric surgery (Fig. 1e, f). General anaesthesia using a combination of shorter acting agents such as sevoflurane and fentanyl, supplemented with caudal analgesics is a popular anaesthetic technique for infants. Babies did not receive any antibiotics pre- or post-operatively except few babies previously admitted for other commodities.

In our institute we attempt laparoscopic hernia repair in toddlers and children, but never in infants. Though the literature is abundant with laparoscopic hernia repair in children, it is limited in neonates as well as in infants at present moment, but however, it is exciting and worth attempting in near future.

Associated other surgeries conducted in 7 (7.8\%) in GI like orchidopexy, congenital cataract surgery, Retinopathy, arthrotomy for septic arthitis, excision of duplicated bladder exstrophy. 5 babies (17.24\%) in GII underwent other procedures like, cervical menigo myelocele repair, cleft palate repair, orchidopexy and ritual circumcision.

We had 2 neonates $(2.24 \%)$ with undescended testis at superficial inguinal pouch where orchidopexies were done in GI and 2 babies (6.8\%) in GII, during same anaesthesia. According to Witherington et al., a patent processus vaginalis with undescended testis is a clear indication for orchidopexy [30].

Ein et al. have reported a recurrence rate of $1.2 \%$, whereas others report 3.8\%. Recurrence rate in incarceration hernias is up to $3 \%$ [32]. We had only one case of $1.12 \%$ recurrence of hernia, in baby with duplicated exstrophy variant 4 months after the procedure, which can be explained due to difficult tissue planes and altered anatomy (Fig. 1d).

Ein had $1.2 \%$ wound infection rates [31]. None of our babies had surgical site infection; including any kind of surgical morbidity or mortality.

As per literature we found incidence of testicular loss or atrophy in $0-19 \%$ [30-32]. We had one baby (0.847\%) with testicular loss, post herniotomy (Mitchell banks' technique) done at day 2 of life in premature baby, noticed 3 months following the procedure. Turk et al. stated that Mitchells Banks' technique is safer in older children [30, 32].

We had one morbidity in a baby with congenital cuts laxa syndrome having direct inguinal hernia where mesh repair was done, required longer time for recovery and discharge from the hospital (0.847\%). Eventually, baby succumbed to other co existing illnesses 8 months following the procedure.
We did not have any mortality directly related to herniotomy procedure in our series.

Limitations of our study: routine ultrasonology and 2D echo cardiography were not done in all the babies pre operatively.

\section{Conclusion}

Inguinal hernia is a common surgical condition in neonates, infants and children; should be referred immediately and managed by tertiary care paediatric centre where round the clock expertise is available. The original Ferguson hernia repair, much used contemporarily, is undoubtedly the excellent operative method for infantile and childhood inguinal hernias with minimal infection and recurrence rates, if done by a paediatric surgeon, as these cases require finer dissection and clear understanding of delicate local anatomy.

\section{Abbreviations \\ DS: down's syndrome; CL: cutis laxa; CTEV: congenital talipus equino varus: RDS: respiratory distress syndrome; HUN: hydroureteronephrosis; GERD: gas- troesophageal reflux syndrome; BLHN: bilateral hydronephrosis; UDT: unde- scended testis; UH: umbilical hernia; HYPO: hypospadias; ROP: retinopathy of prematurity; CHD: congenital heart disease; SLOL: subluxation of lens; $D D H$ : developmental dysplasia of hip; EHBA: extrahepatic biliary atresia; EEC: extro- phy epispadais complex; MMC: myelomengocele; GDD: global developmental delay; CLEFT PL: cleft palte.}

\section{Acknowledgements}

Author would like to thank the Director, paediatric surgical colleagues, paediatric anaesthetists, Radiologists, OT staffs of IGICH, Bangalore, Karnataka, India.

Authors' contributions

DR JSA has contributed whole to the article.

Funding

None.

\section{Availability of data and materials}

The confidential data from the patients is with the corresponding author and is available on request.

\section{Ethics approval and consent to participate}

Ethics approval and consent to participate" obtained from Indira Gandhi Child Health Institute with a number of IGICH 2349000. *Written as well as verbal consent has been taken from caretakers and parents of the babies.

Consent for publication

Not applicable.

Competing interests

The authors declare no competing interests.

Received: 7 January 2020 Accepted: 2 June 2020

Published online: 17 August 2020

\section{References}

1. Groff D, Nagaraj HS, Pietsch JB (1985) Inguinal hernias in premature infants who were operated on before their discharge from the neonatal intensive care unit. Arch Surg 120:962 
2. Grosfeld $J L$ (1989) The current concepts in inguinal hernias in infants and children. World J Surg 13:506-515

3. Grosfeld JL, Minnick K, Shedd F, West KW, Rescorla FJ, Vane DW (1991) Inguinal hernia in children: the factors which affected the recurrence in 62 cases. J Paed Surg 26:283-287

4. Bronsther B, Abrams MW, Elboim C (1972) Inguinal hernias in children-a study of 100 cases and a review of literature. J Am Med Womnes Assoc 27:522-525

5. Poenaru D (2000) Inguinal hernias and hydroceles in infancy and childhood: a consensus statement of the Canadian Association of Paediatric Surgeons. Paedirtr Child Health 5:461-462

6. Ravikumar V, Rajshankar S, Hareesh RS, Kumar N, Gowda MR (2013) A clinical study of the management of inguinal hernias in children on the general surgical practice. J Clin Diag Res 7:144-147

7. Dinesh LJ, Manjunath L, Vikas GK (2014) A study of inguinal hernia in children. Int J Sci Res 3:2149-2155

8. Rowe MI, Copelson LW, Clatworthy HW (1969) The patent processus vaginalis and the inguinal hernia. J Pediatr Surg 4:102-107

9. Rowe MI, Clatworthy HW (1970) Incarcerated and strangulated hernias in children. Arch Surg 101:136-139

10. Hoshino M, Sugito K, Kawashima H, Goto S, Kaneda H, Furuya T, Hosodo T, Masuko T, Ohashi K, Inoue M, Ikeda T, Tomita R, Koshinaga T (2014) Prediction of contra lateral inguinal hernias in children: a prospective study of 357 unilateral inguinal hernias. Hernia 18:333-337

11. Crankson SJ, Al Tawil K, Al Namshan M, Al Jadaan S, Baylon BJ, Gieballa M, Ahmed IH (2015) Management of inguinal hernia in premature infants: 10-year experience. Indian Assoc Pediatr Surg 20:21-24

12. Ballantyne A, Jawaheer G, Munro F (2001) Contralateral groin exploration is not justified in infants with a unilateral inguinal hernia. Br I Surg 88:720-723

13. Kreiger NR, Shochat SJ, McGowan V et al (1994) Early hernia repair in the premature infant: long-term follow-up. J Pediatr Surg 29:978-982

14. Kumar A, Ramakrishnan TS (2013) Single port laparoscopic repair of paediatric inguinal hernias: our experience at a secondary care centre. J Minim Access Surg 9:7-12

15. de Goede B, Verhelst J, van Kempen BJ, Baartmans MG, Langeveld HR, Halm JA, Kazemier G, Lange JF, Wijnen RM (2015) Very low birth weight is an independent risk factor for emergency surgery in premature infants with inguinal hernia. J Am Colloid Surg 220:347-352

16. Vaos G, Gardikis S, Kambouri K, Sigalas I, Kourakis G, Petoussis G (2010) Optimal timing for repair of an inguinal hernia in premature infants. Pediatr Surg Int 26:379-385

17. Lin LY, Chang TJ (2009) Effect of a pediatric surgeon on pediatric inguinal hernia repair-evaluation of the importance of surgeons with subspecialty training by a single-hospital comparative experience. Formos J Surg 42:263-267
18. Ozdemir T, Arıkan A (2013) Postoperative apnea after inguinal hernia repair in formerly premature infants: impacts of gestational age, postconceptional age and comorbidities. Pediatr Surg Int 29:801-804

19. Zamakhshary M, To T, Guan J, Langer JC (2008) Risk of incarceration of inguinal hernia among infants and young children awaiting elective surgery. CMAJ 179:1001-1005

20. Palmer BV (1978) Incarcerated inguinal hernia in children. Ann R Coll Surg Engl 60:121-124

21. Smith G, Wright JE (1996) Reduction of gangrenous small bowel by taxis on an inguinal hernia. Pediatr Surg Int 11:582-583

22. Armas Alvarez AL, Taboada Santomil P, Pradillos Serna JM, Rivera Chávez LL, Estévez Martínez E, Méndez Gallart R et al (2010) Infantile Amyand's hernia presenting as acute scrotum. Circ Pediatr 23:250-252

23. Laing FC, Townsend BA, Rodriguez JR (2007) Ovary-containing hernia in a premature infant: sonographic diagnosis. J Ultrasound Med 26:985-987

24. Osifo OD, Ovueni ME (2009) Inguinal hernia in Nigerian female children: beware of ovary and fallopian tube as contents. Hernia 13:149-153

25. Rescorla FJ, Grosfeld JL (1984) Inguinal hernia repair in the peri nata period and in early infancy: the clinical considerations. J Pediatric Surg 19:832

26. Hadj-Rabia S, Callewaert BL, Bourrat E, Kempers M, Plomp AS, Layet V, Bartholdi D, Renard M, De Backer J, Malfait F, Vanakker OM, Coucke PJ, De Paepe AM, Bodemer C (2013) Twenty patients including 7 probands with autosomal dominant cutis laxa confirm clinical and molecular homogeneity. Orphanet J Rare Dis 8:36

27. Sawaguchi S, Matsunaga E, Honna T (1975) A genetic study on indirect inguinal hernia. Jinrui Idengaku Zasshi 20:187-195

28. Shafei EE (2009) Role of Prolene ${ }^{\circledR}$ Mesh in the repair of recurrent congenital inguinal hernia: a pilot study. Ann Pediatr Surg 1:11-15

29. Witherington R (1984) Cryptorchism and approaches to its surgical management. Surg Clin North Am 64:367-384

30. Ein SH, Njere I, Ein A (2006) Six thousand three hundred sixty-one pediatric inguinal hernias: a 35-year review. J Pediatr Surg 41:980-986

31. Türk E, Memetoglu ME, Edirne Y, Karaca F, Saday C, Güven A (2014) Inguinal herniotomy with the Mitchell-Banks' technique is safe in older children. J Pediatr Surg 49:1159-1160

32. Puri P, Guiney El, O'Donnell B (1984) Inguinal hernia in infants: the fate of the testis following incarceration. J Pediatr Surg 19:44-46

\section{Publisher's Note}

Springer Nature remains neutral with regard to jurisdictional claims in published maps and institutional affiliations.

\section{Submit your manuscript to a SpringerOpen ${ }^{\circ}$ journal and benefit from:}

- Convenient online submission

- Rigorous peer review

- Open access: articles freely available online

- High visibility within the field

- Retaining the copyright to your article

Submit your next manuscript at $\boldsymbol{\nabla}$ springeropen.com 